\title{
SUMMARY OF PANEL DISCUSSION ON SKILLS AND SOCIAL MOBILITY
}

\author{
New Zealand Treasury
}

\section{Panellists:}

David Bromell

Miles Corak

Bronwyn Cross

Roger Kerr

Charles Waldegrave

\section{Chair:}

Tony Burton

\author{
Ministries of Education and Social Development, Institute of Policy Studies \\ University of Ottawa \\ Post-Primary Teachers Association \\ Business Roundtable \\ Family Centre Social Policy Research Unit
}

\section{Panel questions:}

- Our analysis suggests that in order to meet our long-term productivity goals, we will need to achieve a step change in skills levels across our entire population. How can we best achieve this, particularly in the current fiscal context?

- In New Zealand, educational outcomes (participation, attainment) are clearly related to socio-economic status and ethnicity. What can we do to reduce these disparities (and should we focus on disparities by ethnicity or by socioeconomic status, or both)?

- Given that a large part of our current workforce will still be in the workforce in 2020, we will need to focus on upskilling adult employees rather than just focusing on those coming through the school system. What's more, a significant proportion of our current workforce does not have the literacy, language and numeracy skills necessary for full participation in a knowledge society. How can effectively improve foundation skills in the workforce?

- Our economy is changing: knowledge and service sectors are much more important today than ever before, and we are now operating in a global labour market in which competition for skills is intense. What can we do to ensure we are meeting the skills needs of our $21^{\text {st }}$ century economy? (i.e., that supply is matching demand)

\section{Summary}

\section{Introductory statements}

\section{Bronwyn:}

The opportunities we have today are not the same as they used to be
- Science education is very important.

- $\quad$ NCEA has focused on success, but upper decile schools are switching to international qualifications systems.

- Schools Plus has been good for encouraging collaboration across the education sector.

- Tomorrow's Schools has led to polarisation across ethnic lines.

- $\quad$ Schools need investment in broadband more than homes.

Roger:

- Notes that Miles's work demonstrated that the US, which spends the most on education, has the lowest social mobility - casts doubt on the idea that more spending on education is necessarily better and supports Miles's view that the spending therefore needs to be progressive (and that subsidies to tertiary education are not progressive).

- $\quad$ Philosophical questions around social mobility how little is too little, how much is too much? No normative grounding.

- Emphasis on reducing barriers to potential is positive, but productivity is only part of the story. Openness, freedom (economic and personal). competition and choice also crucial.

- 'We' emphasis in Treasury material suggests central planning/social engineering, as opposed to freedom and choice.

Miles:

- Productivity is essentially a means to an end - but what is this end?

- Freedom is important too - as both a goal, and an instrument (Amartya Sen)

- What would freedom mean from a child's point of view? Freedom to become all that you would like to become, without being tied to family background. 
- How to ensure this (private, public - matters less than ensuring that interventions are effective).

- In the OECD (how independent?), social policy has moved from static to dynamic, from passive insurance based policies, to active investment based policies.

- Policy also needs to create a sense of security throughout the lifecourse. This means that insurance type social policies will remain important, but so will more active investments throughout peoples' lives. In terms of education, this means not just early childhood education, but follow up through school and into adulthood.

\section{Charles:}

- Skills are an important aspect of the living standards equation, but need to be seen as part of a bigger picture, which includes worker-friendly environments, investments in technology, increasing the workforce etc.

- The broader context for skills is also important: two life cycle issues that are significant are child poverty and our aging society.

- Child poverty: Working for Families has made some good inroads into our levels of child poverty It has almost halved from 33\% when we (NZ Poverty Measurement Project) first identified it in 1995 to $17 \%$ in 2007 . but $17 \%$ is still too many under the poverty line. We need to maintain momentum, especially because we know about the intergenerational effects of child poverty - as demonstrated by Cathy Wiley's Competent Children, Competent Learners study. Shows that educational and/or income advantages early in life continue through the lifecycle.

- Neurological and cognitive developmental deficits for children, as a result of abuse and neglect, are increasingly being understood in research. The Dunedin longitudinal study shows that effects that start early are worse (e.g. anti-social disorder beginning in childhood has worse impacts than if it starts in teenage years).

- Ageing: older, Pakeha superannuitants will become reliant on the younger, growing Māori. Pacific and Asian population in the labour market. This will require work to continue to improve educational outcomes for these populations and improved race relations. Also, although some people will be able to keep on working beyond the traditional age of retirement, others, such as labourers, will have a finite working life due to physical wear and tear.

\section{David:}

- We need to raise our skill levels - but which skills matter? And what works best to develop them?

- Education is about more than just producing more efficient workers, it is also about creating citizens who can think, reason, question and participate in our democracy and society. How can we ensure that education supports these broader social goals and public goods?

- As we move towards an economy that is based more on knowledge and services, non-cognitive skills (conscientiousness, the ability to learn, interpersonal skills and communication with colleagues and clients, self-responsibility, work habits, etc) become more important. But how do we cultivate these?

- $\quad$ Early intervention is key, particularly for children from disadvantaged backgrounds (e.g. post-natal support, paid parental leave, parenting skills education, early childhood education).

- Shifting funding to early intervention from inefficient and regressive policies (universal, interest-free student loans, fee subsidies for older adults) would be a good start

- How do we prevent NZ from becoming a 'skills incubator' for other national economies - training people who then head overseas? We need to have a more joined up approach across a range of policy areas including tax, immigration, education, research, science and technology, labour market regulation and workplace practices.

- Skills development is important, but so is skills utilisation (management skills).

\section{Opens up to questions from the floor}

\section{Question on the link between Tomorrow's Schools} and educational disparities:

- Bronwyn: the devolved Tomorrow's Schools model exacerbates disparities because of the funding model, and because of community capture of the system with little oversight body to secure the public good. Gives an example from Edmington.

- Roger: Tomorrow's Schools was a botched reform. What is required is greater parental choice and a more flexible education system, as well as stronger institutions, e.g. a Mexican immigrant is much more productive in the US than in Mexico because of the better institutions.

\section{Question on standards of living and climate change:}

- Tony: growth is a means to a higher standard of living. There are limited areas the government can get involved in, and there is little money to spend, so we need to identify areas of effective expenditure. Climate change is an area of policy focused on elsewhere in Treasury.

- Charles: climate change is an important consideration, a public goods question. Social mobility connects concerns of private and public goods.

\section{Question on returns to university education:}

- $\quad$ Roger: the literature suggests that investing early has the best returns. Gary Becker continues to point out that the returns to higher education are mostly private, and also writes on the importance 
of family structure, suggesting that a two parent family is typically (not always) the most effective. Miles: access to university education is not hampered by fees. Benefits are mostly private, therefore free university is not necessarily the most efficient use of funds - early intervention is better. But what is most effective? Evaluations of early interventions suggest that some provide just short term results, some provide long term ones, if followed through. Where is the border between family and state?

Bronwyn: competitive education systems usually offer schools choice (ie to choose the most desirable students) but less real choice for parents. Charles: while early investment does give the best returns, it does not mean that later investment is not also important. Also, as Cathy Wiley's study demonstrates, there needs to be investment in noncognitive skills like curiosity, persistence, etc.

David: currently the balance of public education expenditure is $35 \%$ tertiary, $46 \%$ schooling and $9 \%$ early childhood education. The Competent Learners longitudinal study indicates that cognitive skill development at age 5 is reflected in cognitive skills at age 16, with some scope for improvement between ages 5 and 8 . Noncognitive skills are amenable to later intervention, provided modes of teaching and learning and management practices in the workplace support these.

\section{Question on the future of education:}

Bronwyn: we need to stimulate interest in science, maths and technology.

Charles: we need to both target the tail of underachievement and disadvantage, and develop different workplace practices and up-skilling/retraining for older people to enable them to continue contributing.

David: we need to develop a more finely grained analysis of disadvantage, one that goes beyond the polarised and sterile debate about SES vs. ethnicity as proxies for (or causes of) disadvantage. And if for now the most important issue is raising labour productivity to drive economic growth, can we go about this in ways that build stronger foundations for realising higher-order public goods in the future?

- Miles: interventions need to be relatively more targeted towards the disadvantaged. On the face of it, decile funding seems like a good way to do this. There is always an onus on the government to demonstrate that interventions are effective, so we need to build evaluations into the schemes we put in place to ensure that they are successful.

- Roger: labour market flexibility is important for innovation and productivity - 90 day probation periods are normal in the OECD. 